\title{
Medical Education at the University of São Paulo Medical School
}

\author{
José Otávio Costa Auler Jr. ${ }^{1}$, Edmund Chada Baracat ${ }^{2}$, Joaquim Edson Vieira ${ }^{3}$
}

The University of São Paulo Medical School (FMUSP) started in 2015 a new undergraduate medical curriculum. This model reduces the time allotted to lectures and increases the time devoted to tutored discussions and to clinical reasoning, without neglecting the need to acquire information and scientific foundations that guide the practice of medicine, always grounded by the best evidence. The proposal is anchored in principles resulting from Medical Education research, and as a result of large and numerous meetings with teachers and students, besides international experts support.

In practice, its background considers the need for systematic education during the six undergraduate years, focusing on information and fundamental skills of medical knowledge and centralizing the process on the student, who must know how to keep his/her continuing learning skills (learning to learn). The FMUSP curriculum also addresses the theme "Social Determinants of Health" [http://www. ssrn.com/en/] that have become more frequent in the medical literature and point significantly to the need of studying and researching this topic by new generations of health professionals ${ }^{1}$.

The FMUSP curriculum is the result of an institutional design that involves the Medical School and three University Institutes, the Biomedicine (ICB), Chemistry (IQ), and Biosciences (IB). The main objectives that underpin this curriculum aims that professionals whose medical education has been from University of São Paulo must:

1. Develop a critical analysis and be ready to an active pursuit of knowledge;

2. Communicate effectively with patients, community and health teams;

3. Be able to recognize their social role as a medical professional in the health system;

4. Conduct and properly implement strategies for prevention, diagnosis and treatment;

5. Work collaboratively in multidisciplinary teams;

6. Be able to integrate and analyze the basic principles of medical knowledge into the context of health care;

7. Generate and produce valuable knowledge;

8. Have a critical view of his medical practice;

9. Act as leaders and educators in their fields;

10. Demonstrate professionalism, ethics and decision awareness.

In order to achieve these goals, teachers and administrative staff, along with students, have launched complementary educational strategies:

1. Integration of areas of knowledge by means of, at least, sharing the programs ${ }^{2,3}$;

2. A structure of a "Z" curriculum, where areas

\footnotetext{
1. Professor of Anesthesiology, Department of Surgery, Dean - University of São Paulo Medical School.

2. Professor of Gynecology, Department of Gynecology and Obstetric, University of São Paulo Medical School.

3. Professor of of Anesthesiology, Department of Surgery, University of São Paulo Medical School.

Mailing address: Av. Dr. Arnaldo, 455 - Cerqueira César. São Paulo, SP, Brasil. CEP: 01246-903.
} 
considered basic, or hard sciences, constitutes the most part of the beginning years, while the clinical years constitute the most part of the final years, within a transition framework, mimicking a "Z" letter";

3. Continuing assessments, which goal is to integrate the knowledge reached so far and show the clinical applications of those.
In this new curriculum we want to be even closer to the society to offer the highest levels of health care, a relevant scientific production as well as to participate in the social development with ethics, humanism and transparency. University of São Paulo Medical School wants to keep its leadership and ensure to provide the best doctors, the best scientists and the best citizens to serve our society.

\section{REFERENCES}

1. Vieira JE, Silva LF, Baracat EC. Medical education at the University of São Paulo Medical School. Clinics (Sao Paulo). 2015;70(4):229-30. doi: 10.6061/clinics/2015(04)01.

2. Harden RM. The integration ladder: a tool for curriculum planning and evaluation. Med Educ. 2000;34(7):551-7. doi: 10.1046/j.1365-2923.2000.00697.x.

3. Wilkerson L, Stevens CM, Krasne S. No content without context: integrating basic, clinical, and social sciences in a pre-clerkship curriculum. Med Teach. 2009;31(9):812-21. doi: 10.1080/01421590903049806.

4. Ten Cate O. Medical education in The Netherlands. Med Teach. 2007;29(8):752-7. doi: 10.1080/01421590701724741. 